\title{
Cyclosporine A impairs bone repair in critical defects filled with different osteoconductive bone substitutes
}

\section{Fernanda Castanheira GONÇALVES(a) Guilherme José Pimentel Lopes de OLIVEIRA ${ }^{(\text {b) }}$ \\ Cassio Rocha SCARDUELI(a) (iD
Rubens SPIN-NETO(c) (D) \\ Andreas STAVROPOULOS(d) (iD Rosemary Adriana Chiérici MARCANTONIO(a) (D)}

(a) Universidade Estadual de São Paulo Unesp, School of Dentistry Araraquara, Department of Diagnosis and Surgery, Araraquara, SP, Brazil.

(b) Universidade Federal de Uberlândia - UFU, Dental School, Department of Periodontology, Uberlândia, MG, Brazil.

(c)Aarhus University, Department of Dentistry and Oral Health, Section of Oral Radiology, Aarhus, Denmark.

(d) Malmo University, Department of Community Dentistry and Periodontology, Malmö, Sweden.

Declaration of Interests: The authors certify that they have no commercial or associative interest that represents a conflict of interest in connection with the manuscript.

\section{Corresponding Author:}

Rosemary Adriana Chiérici Marcantonio

E-mail: adriana@foar.unesp.br

hitps://doi.org/10.1590/1807-3107bor-2020.vol34.0007

Submitted: April 3, 2019

Accepted for publication: November 1, 2019

Last revision: November 8, 2019
Abstract: The aim of this study was to assess the influence of cyclosporine administration on the repair of critical-sized calvaria defects (CSDs) in rat calvaria filled with diverse biomaterials. Sixty animals were divided into two groups: the control (CTR) group (saline solution) and the cyclosporine (CCP) group (cyclosporine, $10 \mathrm{mg} / \mathrm{kg} /$ day). These medications were administered daily by gavage, beginning 15 days before the surgical procedure and lasting until the day the animals were euthanized. A CSD $(5 \mathrm{~mm} \varnothing)$ was made in the calvaria of each animal, which was allocated to one of 3 subgroups, according to the biomaterial used to fill the defect: coagulum (COA), deproteinized bovine bone (DBB), or biphasic calcium phosphate ceramics of hydroxyapatite and $\beta$-phosphate tricalcium (HA/TCP). Euthanasia of the animals was performed 15 and 60 days after the surgical procedure $(n=5$ animals/period/ subgroup). Bone repair (formation) assessment was performed through microtomography and histometry, while the analyses of the expression of the BMP2, Osteocalcin, and TGF $\beta 1$ proteins were performed using immunohistochemistry. The CSDs not filled with biomaterials demonstrated lower bone formation in the CCP group. At 15 days, less bone formation was observed in the CSDs filled with DBB, a smaller volume of mineralized tissue was observed in the CSDs filled with $\mathrm{HA} / \mathrm{TCP}$, and the expression levels of BMP2 and osteocalcin were lower in the CCP group compared to the CTR group. The use of cyclosporine impaired bone repair in CSD, and this effect can be partially explained by the suppression of BMP2 and osteocalcin expression.

Keywords: Bone Regeneration; Bone Substitutes; Immunosuppression.

\section{Introduction}

Solid organ transplantation is the procedure of choice for the treatment of terminal diseases that can lead to death of the host. ${ }^{1}$ To effectively transplant organs, specific blockage of the immune system is necessary to avoid rejection of the transplanted organ. ${ }^{1}$ Immune reactions are blocked through the use of immunosuppressive drugs, such as cyclosporine, which has been shown to effectively avoid the rejection of organs, such as the heart, ${ }^{2}$ liver, ${ }^{3}$ and kidney. ${ }^{4}$ This drug has a mechanism of action that is based on the blockade of the calcineurin formation, which is an 
intracellular protein that participates in the induction of differentiation and proliferation of Tlymphocytes. ${ }^{5,6}$ However, the use of cyclosporine A has also been related to the reduction of the expression of proteins related to the formation and maturation of bone tissue, ${ }^{7,8}$ reduction of vitamin D levels, ${ }^{7}$ reduction of osteoblastic differentiation and activity, ${ }^{6,9}$ and an increased number of osteoclasts..$^{10}$ These effects of cyclosporine A may induce imbalance of bone turnover and, consequently, lead to a reduction of bone mineral density, ${ }^{11}$ and fractures of the long bones. ${ }^{12}$

The increased life expectancy of transplanted patients has increased the number of individuals who may undergo oral rehabilitation treatment with osseointegrated implants and bone grafts. ${ }^{13}$ Preclinical studies have shown conflicting results about the effect of cyclosporine A on osseointegration. It has been observed that cyclosporine consumption did not interfere ${ }^{14}$ or harm the establishment ${ }^{15}$ and maintenance of osseointegration. ${ }^{15,16} \mathrm{~A}$ clinical study has shown that the use of cyclosporine did not interfere with the osseointegration process or in the clinical outcomes of implant-supported prosthesis installed in transplanted patients after 1 year of follow-up, ${ }^{13}$ suggesting that the use of cyclosporine A may not interfere with the short-term success rates of dental implants.

However, note that the direct placement of implants in the native bone of the host is not always possible, and when these situations occur, it is necessary to use bone substitutes to promote a bone availability compatible with the installation of implants in a proper position. ${ }^{17}$ The effect of cyclosporine A on the healing of areas grafted with bone substitute materials has not been explored in detail. The use of cyclosporine A has been previously evaluated in a preclinical study in a pig model to evaluate its potential to avoid rejections of vascularized homogenous bone grafts, and this drug has been shown to be effective in preventing rejection of the portion of the grafted bone, however, cyclosporine A use was associated with the reduced mineral density of the graft. ${ }^{18}$

It has also been shown that the use of cyclosporine did not impair the healing of non-critical defects in rat femurs filled with $\beta$-tricalcium phosphate associated with bone marrow aspirates ${ }^{19}$ or filled with xenogeneic and homogenous grafts. ${ }^{20}$ Due to the limited information about the effect of the use of cyclosporine $\mathrm{A}$ on bone repairs in grafted areas with xenogenic and alloplastic bone substitutes, the aim of this study was to assess the influence of cyclosporine A administration on the repair of critical-sized calvaria defects (CSD) in rats filled with coagulum (COA), deproteinized bovine bone (DBB) and biphasic calcium phosphate ceramics of hydroxyapatite and $\beta$-phosphate tricalcium (HA/TCP).

\section{Methodology}

\section{Animal allocations and groups}

In the present study, sixty adult male rats (Rattus norvegicus var. albinus, Holtzman) approximately 4 months of age were used. The animals presented with body masses between 350 and 400 grams and were kept in an environment with controlled light and temperature cycles. Ad libitum access to rat chow and water was maintained before and during the experimental period. This study was approved by the Ethics Committee on the Use of Animals (CEUA $n^{\circ} 01 / 2012$ ).

The animals were randomly allocated to 2 groups (30 animals in each group), according to the type of medication used: the control (CTR) group (saline solution) and the cyclosporine A (CCP) group (10 mg/kg/day of cyclosporine A, Sandimmune ${ }^{\circledR}$, Novartis Pharma AG, Rotkreuz, Switzerland). The saline solution and the drug were applied daily by gavage starting 15 days before the surgical procedures and continuing until the day of euthanasia.

At the moment of the surgical procedures, after the preparation of the CSDs, the animals in each group were randomly divided into subgroups (with 10 animals each), according to the type of biomaterial used to fill the CSDs: COA (coagulum), DBB (deproteinized bovine bone, Bio-Oss ${ }^{\circledR}$, Geistlich AG, Wolhusen, Switzerland), and HA/TCP (biphasic calcium phosphate ceramics of hydroxyapatite and $\beta$-phosphate tricalcium (Bone Ceramic ${ }^{\circledR}$, Straumann AG, Basel, Switzerland)). The animals were submitted to euthanasia at 15 and 60 days after the surgical procedure ( $\mathrm{n}=5$ animals/group/period). 


\section{Surgical procedures}

The animals were anesthetized using a combination of ketamine $(0.08 \mathrm{ml} / 100 \mathrm{~g}$, Francotar, Virbac do Brasil Ind. Com. Ltda, São Paulo, Brazil) with xylazine (0.04 ml/100 g, Virbaxyl 2\%, Virbac do Brasil Ind. Com. Ltda, São Paulo, Brazil). A surgical access was created on the anterolateral portion of the calvaria to expose the bone tissue. Then, a 5-mm circular bone defect was made in the lateral portion of the calvaria in the parietal bone, immediately after the vertex of the coronal suture of the animal by the same single operator (GJO). After the insertion of the biomaterials in the CSDs, all defects were covered with the periosteum and sutured in planes. For postsurgical care, the animals received a single dose of MultiBiotic (Subcutaneous: $0.3 \mathrm{ml} / \mathrm{kg}$; Pentabiotico Veterinario Veterinária, Zoetis Dodge, São Paulo, Brazil) and two doses of sodium dipyrone (IM- $12 \mathrm{~h}$ : $0.6 \mathrm{ml} / \mathrm{kg}$; Ibasa, Porto Alegre, Brazil). Fifteen and 60 days after the surgical procedure, the animals were submitted to euthanasia, and their calvaria were harvested en bloc. The calvaria were then fixed in $4 \%$ paraformaldehyde for approximately 48 hours and stored in alcohol $70^{\circ}$.

\section{Micro-computed tomography $(\mu \mathrm{CT})$}

The calvaria were scanned with microcomputed tomography (SkyScan Micro-CT, Kontich, Belgium) with the following parameters: camera pixel 12.45, X-ray tube potential $65 \mathrm{kVP}, \mathrm{X}$-ray intensity $385 \mu \mathrm{A}$, integration time $300 \mathrm{~ms}$, filter Al- $1 \mathrm{~mm}$, and voxel size $18 \mu \mathrm{m}^{3}$. The generated images were reconstructed, spatially reoriented and analyzed with specific softwares (NRecon/DataViewer/CTan, Skyscan, Aartselaar, Belgium). The volume of the mineralized tissues was obtained within a circular region of interest ( $5 \mathrm{~mm}$ in diameter), which encompassed the entire thickness of the calvaria, using a threshold of 65-255 of the grayscale as a reference for the mineralized tissue. This analysis was performed by a blinded and trained examiner (FCG).

\section{Histomorphometry}

After the scanning, the calvarias were decalcified in EDTA 7\% for 12 weeks and then submitted to laboratory processing for inclusion in paraffin. The samples were cut at a thickness of $5 \mu \mathrm{m}$ and stained using the hematoxylin \& eosin (HE) technique. Six histological sections that were $240 \mu \mathrm{m}$ apart were used for the histometry analysis. The histological images were captured with the aid of an optical microscopy (DM 2500, Leica-Reichert \& Jung products, Wetzlar, Germany), with a 25x magnification. The images were measured using ImageJ software (San Rafael, USA). The area of the original defect was determined by referencing the reversion lines that marked the new bone formation. The quantity of tissues that filled the defect (bone and biomaterial) was determined through histometric analysis, as a percentage relative to the original area of the defect. This analysis was performed by a blinded and trained examiner (FCG).

\section{Immunohistochemistry}

Histological sections measuring $5 \mu \mathrm{m}$ in thickness were prepared for immunohistochemical evaluation bone morphogenetic protein (BMP-2), osteocalcin $(\mathrm{OCN})$ (and transforming growth factor $\beta 1$ (TGF $\beta 1$ ). A descriptive analysis was performed based on a score of the extent of the staining, which represented the protein expression levels: (0) absent, (1) mild, (2) moderate, and (3) strong, which represented $0 \%, 0-20 \%, 20-60 \%$ and above $60 \%$ of cellular and matrix marking, respectively. ${ }^{21}$ These analyses were performed in three areas that were randomly selected for the evaluation: two at the periphery of the defects (which included neoformed bone tissue and the connective tissue associated with the biomaterial) and one at the center of the defect (which included the connective tissue, biomaterial, and new bone). This evaluation was executed with the aid of an optical microscope (DM 2500, Leica-Reichert \& Jung products, Wetzlar, Germany), with 400x magnification of the original augmentation. The mean of the 3 values obtained was considered to be the value of the sample. The extent of staining was recorded by a trained and blinded examiner for the experimental groups (GJO).

\section{Statistics}

All data from this study were evaluated using non-parametric tests. The Kruskal-Wallis test supplemented by the Dunn test was used for 
between-group evaluations in each evaluation period, and the Mann-Whitney test was used for evaluations within each group by varying the experimental period. GraphPad Prism 5.0 software (San Diego, CA, USA) was used for the statistical tests. All tests were performed with the confidence level set at $95 \%$.

\section{Results}

All animals survived and supported the experimental tests. Thus, all the samples were used in the analysis proposed.

\section{Microcomputed tomography}

The use of cyclosporine-induced a lower volume of mineralized tissues in the COA subgroups in both periods and in the HA/TCP subgroup at the 15-day evaluation compared to the $\mathrm{CTR}$ group. In both groups (CTR and CCP), the CSDs filled with DBB presented higher volumes of mineralized tissues than the COA subgroups in all evaluation periods (Figure 1).

\section{Histomorphometry}

The use of cyclosporine was associated with a lower amount of bone tissue in the COA subgroups in both experimental periods and in the DBB subgroup at the 15-day evaluation. The DBB subgroup presented lower amounts of bone tissue than the COA subgroup at 60 days in the CTR group and in both evaluation periods in the CCP group. The HA/TCP subgroup presented lower percentages of bone than the COA subgroup at 15 days in the CTR group. The use of cyclosporine did not alter the amount of biomaterial in the repaired tissue in relation to the CTR group. However, there was a tendency toward a greater amount of DBB at 15 days and of HA/TCP at 60 days in the CCP group $(\mathrm{p}=0.09)$ (Figure 2).

\section{Immunohistochemistry}

The administration of cyclosporine promoted a reduction in the expression of BMP2 and OCN in relation to the CTR group. The COA subgroup of the CTR group presented a higher expression of BMP2 at 15 days and of OCN in both evaluation periods compared to the same subgroup of the CCP group. At 15 days, the DBB subgroup of the CTR group had higher expression of BMP2 and OCN in relation to the same subgroup in the CCP group. It was also verified in the HA/TCP subgroup that the animals in the CTR group presented higher expression of BMP2 (60 days) and of OCN (15 days) in relation to the same subgroup in the $\mathrm{CCP}$ group. There were no between-group differences in the TGF $\beta 1$ expression (Figure 3). Images representing the BMP2, OCN, and TGF $\beta 1$ expression levels in the CTR and CCP groups are provided in Figures 4 and 5 , respectively.

\section{Discussion}

This study demonstrated that in general, the use of cyclosporine A reduced the formation of bone tissue in CSD filled with coagulum and DBB and delayed the formation of repaired tissue in CSD filled with HA/TCP. In addition, a tendency that the use of cyclosporine A reduced the resorption of biomaterials was shown, which may have contributed to a lower amount of bone tissue primarily observed in the CSDs filled with DBB.

The reduction of bone formation observed in CSDs filled with coagulum in the CCP group may have occurred because of the known effects of cyclosporine $\mathrm{A}$ in reducing the differentiation and activity of osteoblasts. ${ }^{9,22}$ These results corroborate with preclinical studies of rabbits, which have demonstrated that the use of cyclosporine A delays the process of osseointegration ${ }^{23}$ and may even reduce the quality of bone tissue around implants that were previously osseointegrated. ${ }^{15,16}$ An important fact is that in vitro studies have demonstrated that cyclosporine A has an inducing effect of bone tissue formation as a consequence of increased osteoblastic activity, ${ }^{6}$ whereas a preclinical study and a clinical study have demonstrated that the use of cyclosporine A did not adversely affect the process of osseointegration ${ }^{14}$ and did not interfere in the success rates of implants installed in transplant patients after one year of follow-up. ${ }^{13}$ Cyclosporine A have as an mechanism of action the inhibition of the calcineurin partway due to specific blockage of the Nuclear Factor of Activated T Cells (NFAT) ${ }^{6}$ 


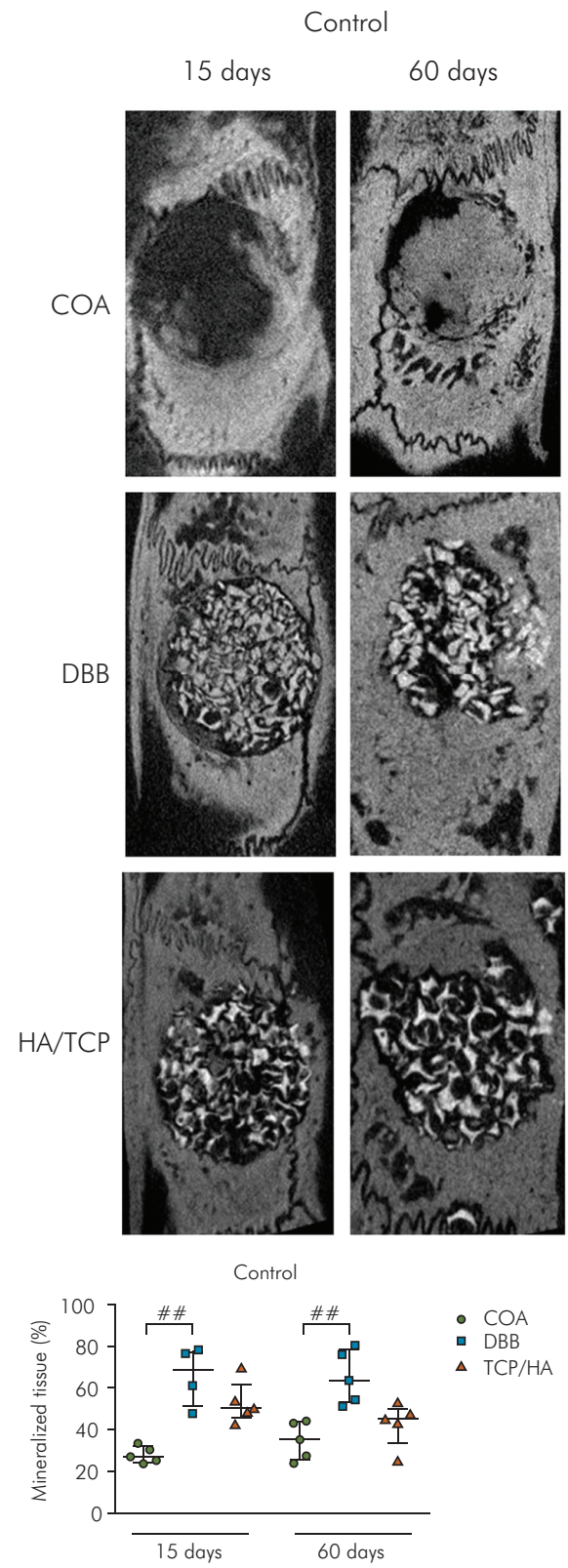

Ciclosporin $A$
15 days $\quad 60$ days
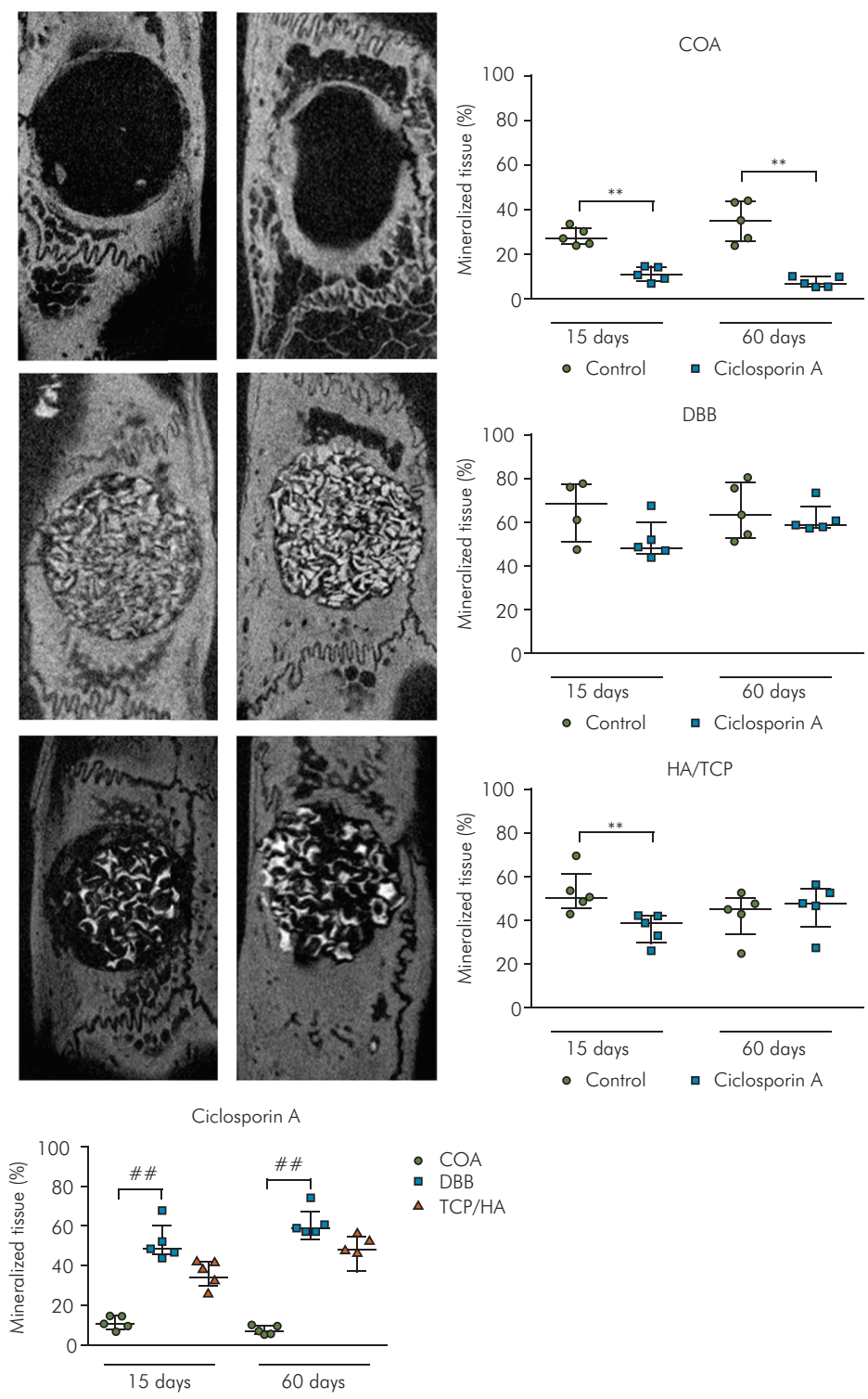

Figure 1. Representative images and graphs of $\mu \mathrm{CT}$ analysis. It is possible to observe that the use of cyclosporine reduced the volume of mineralized tissue in the COA subgroup and in the HA/TCP subgroup in relation to the control group. The use of DBB increased the amount of mineralized tissues within the area of interest compared to the defects filled only by the coagulum. In the bar-graphs, significant between-group differences are indicated by the connecting brackets ** $p<0.01$ (Mann-Whitney test); \# \#p $<0.01$ (Kruskal-Wallis and Dunn's test).

that is an active transcriptional complexes in the nucleus which is essential for driving osteoblasts differentiation due to the latter expression of the osterix gene. ${ }^{24}$ Note that the effect of cyclosporine A on bone tissue metabolism is dose-dependent, and lower doses are related to the increased osteoblastic activity due to the inefficacy of the low concentrations of cyclosporine A to overexpress the NFATc1, and higher doses are related to suppression of this stimulus due to the reduction of the expression of the NFAT. ${ }^{6}$ It is likely that the dosage used in this study influenced the formation of bone tissue in 


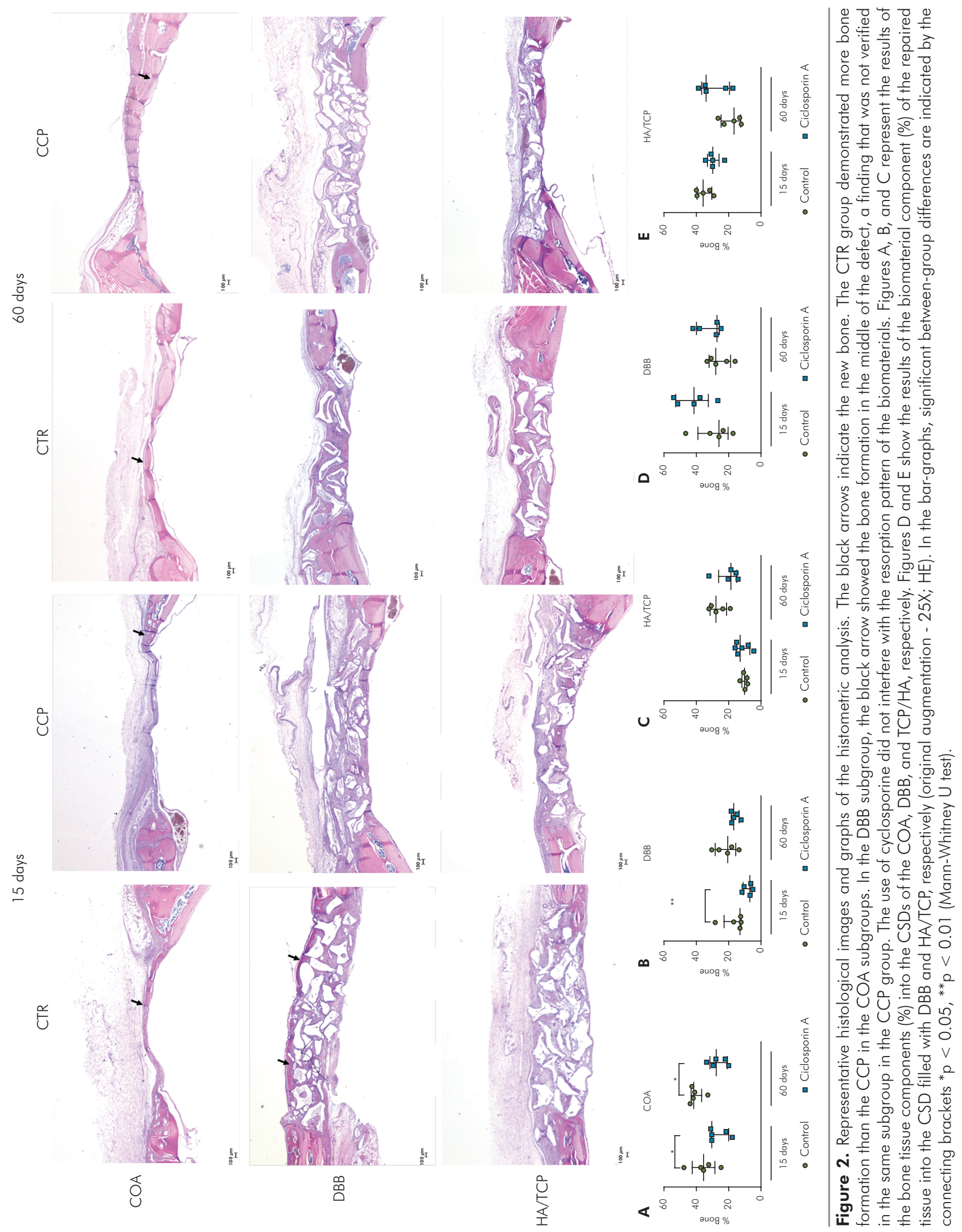


COA

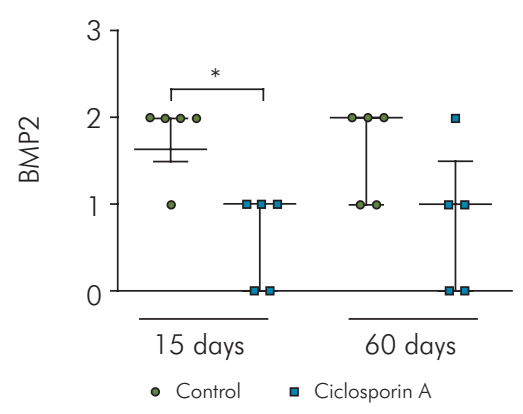

DBB

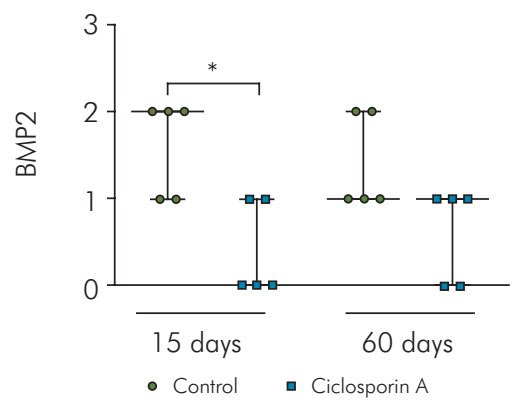

HA/TCP

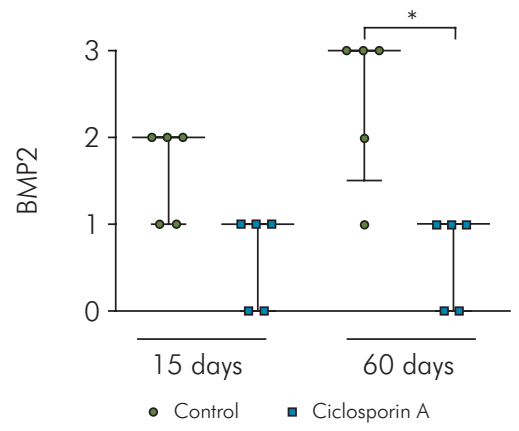

COA

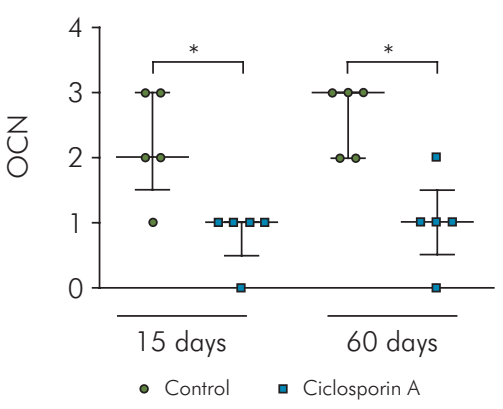

DBB

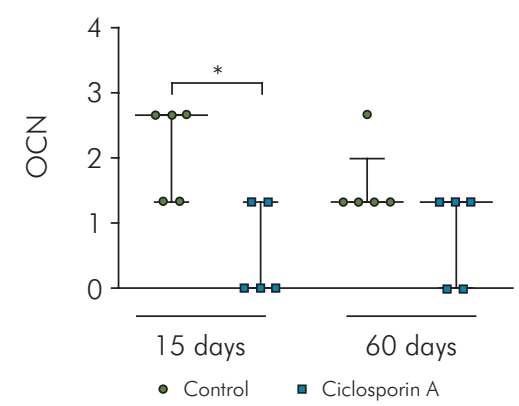

HA/TCP

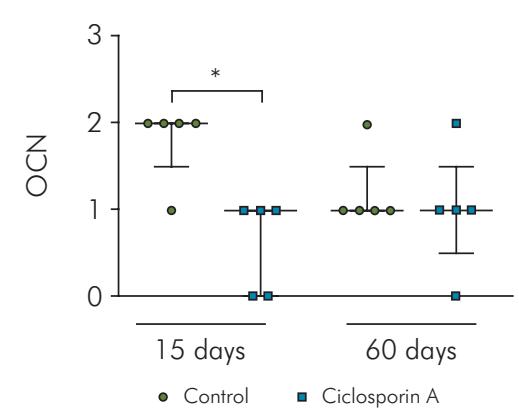

COA

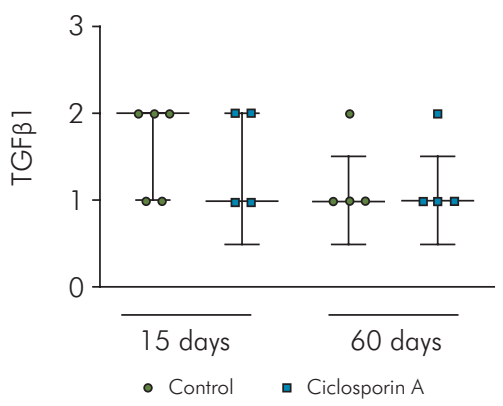

DBB

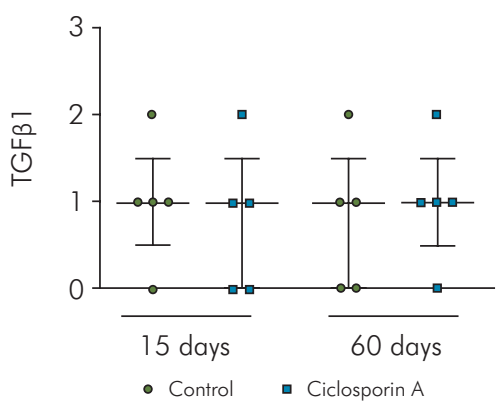

HA/TCP

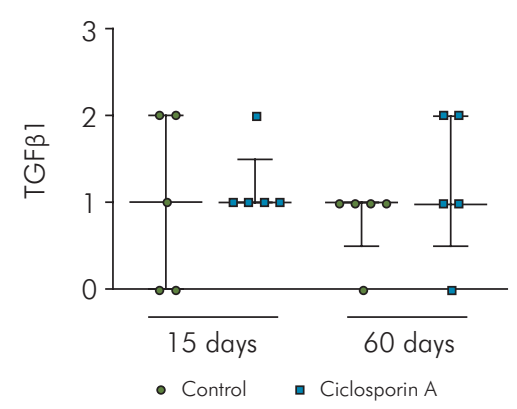

Figure 3. Representative graphs of the expression levels of the proteins BMP2, OCN, and e TGF $\beta 1$. In general, there was less expression of BMP2 and OCN at the 15-day mark in the CCP group. It was also observed that the CCP group demonstrated decreased expression of BMP2 in the HA/TCP subgroup and OCN in the COA subgroup than the same subgroups in the CTR group. There were no differences in the expression of the TGF $\beta 1$. In the bar-graphs, significant between-group differences are indicated with the connecting brackets * $p<0.05$ (Mann-Whitney $U$ test).

CSDs because the same dosage used in this study has hampered the osseointegration process in other studies. $15,16,23$

The use of bone substitutes has been indicated to promote bone volume availability to allow the dental implants placement. ${ }^{17,25,26}$ In fact, the use of biomaterials to fill the CSDs promoted a higher volume of mineralized tissues compared to CSDs that were not filled with DBB and HA/TCP in the
CTR and CCP groups, however, this higher volume of mineralized tissues was only statistically significant when the CSDs were filled with DBB. The higher volume of mineralized tissues associated with DBB use is related to the lower resorption rates of this biomaterial compared to the HA/TCP, as demonstrated in other studies. ${ }^{27,28}$

Another important finding of this study is that in the CCP groups, the biomaterials tended to be 
(-) Control

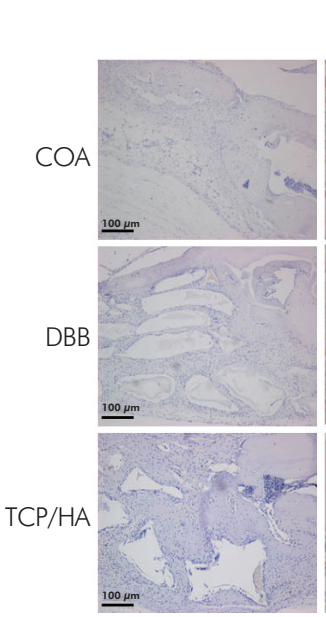

BMP2

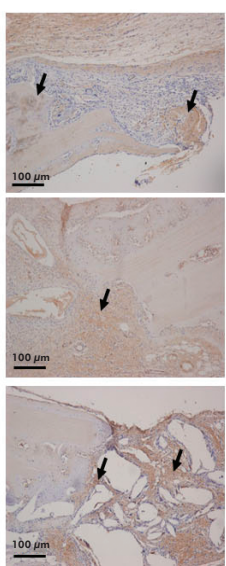

60 days

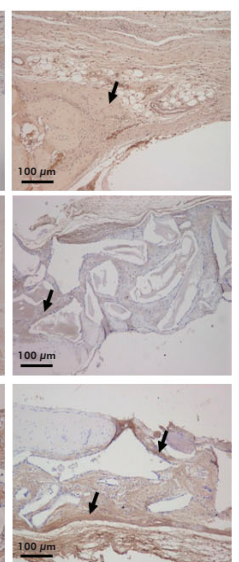

$\mathrm{OCN}$

15 days

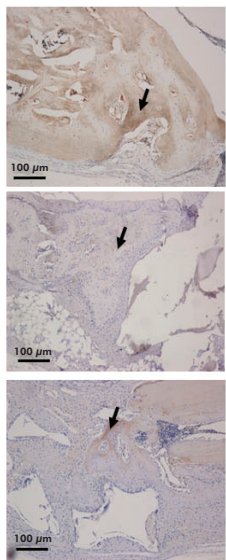

60 days

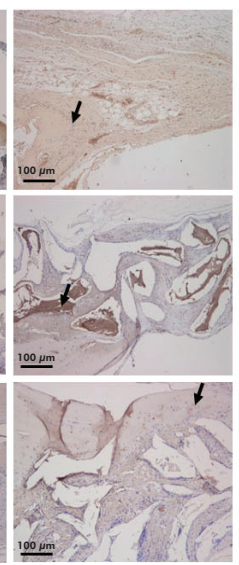

TGF 1

15 days

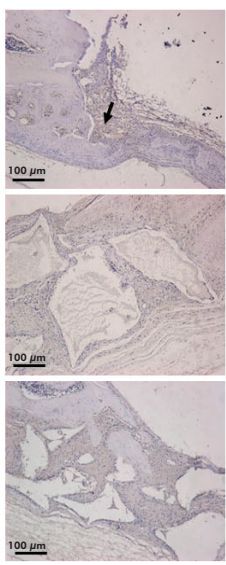

60 days

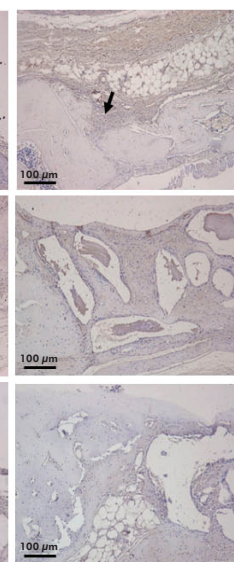

Figure 4. Panel of the representative images of expression of the proteins BMP2, OCN and TGF $\beta 1$ of the CTR group. The black arrows point to sites where the brown staining marks the proteins. Note that BMP2 is primarily expressed in connective tissue at the margins of the defect, around the biomaterial particles, and in the matrix of the new bone. OCN was primarily expressed in the matrix of the bone tissue, whereas TGF $\beta 1$ was weakly expressed in the cells and in the connective tissue matrix on the edges of the CSD (original magnification, 100x).

\section{Cyclosporine A}

(-) Control

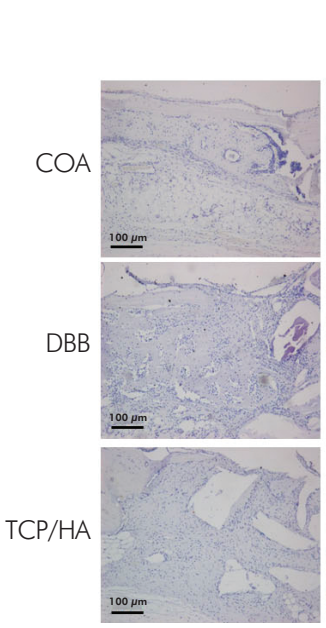

BMP2

$$
15 \text { days }
$$
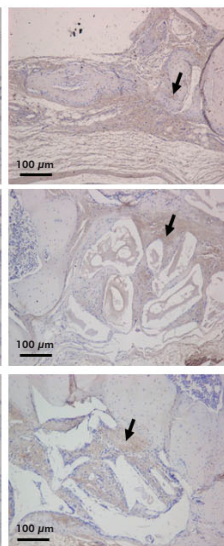

60 days

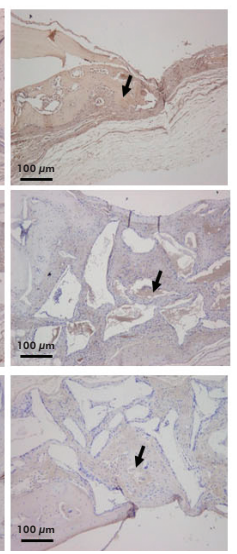

$\mathrm{OCN}$

15 days
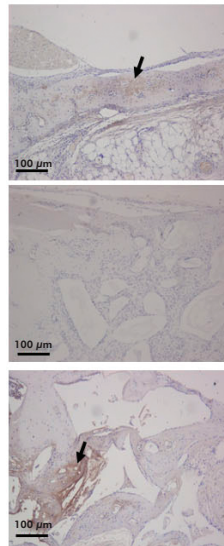

60 days

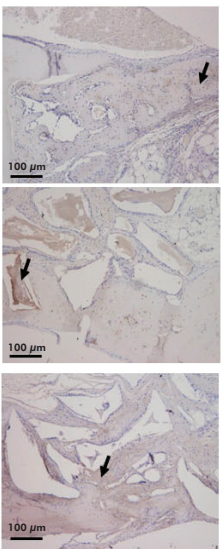

TGF $\beta 1$

15 days

60 days

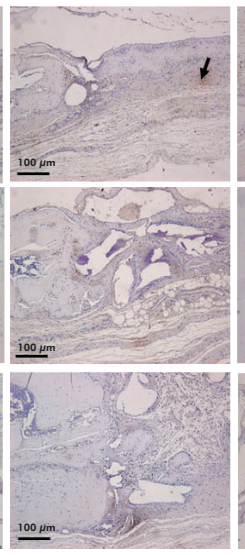

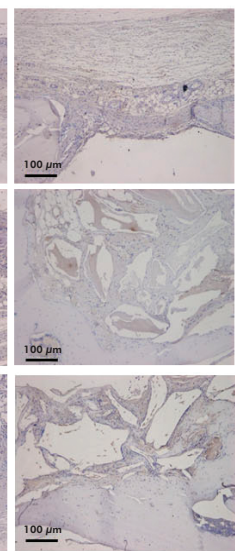

Figure 5. Panel of the representative images of the expression levels of the proteins BMP2, OCN and TGF $\beta 1$ of the CCP group. The black arrows point to sites where the brown staining mark the proteins. It was found that BMP2, OCN, and TGF $\beta 1$ showed similar expression sites as in the CTR group, however, the BMP2 and OCN expression levels were weak compared with the CTR group (original magnification, 100x).

resorbed with greater difficulty, a fact that has not been observed in other studies. Preclinical studies have demonstrated that the use of cyclosporine A did not induce greater resorption of bone substitutes of xenogenic and homogenous origin ${ }^{20}$ and alloplastic origin enriched with aspirate of bone marrow, ${ }^{19}$ 
and it did not alter the formation of bone tissue when the above-mentioned bone substitutes were used to fill non-critical defects in rat femurs. $18,19,20$ Vossen et al. ${ }^{18}$ have demonstrated that although the use of cyclosporine reduced bone density of a homogenous vascularized graft of radio in a pig model, it prevents the graft rejection, allowing its remodeling and reestablishment of its function. Other factors, such as different types of biomaterials, different types of defects and different dosages of cyclosporine $\mathrm{A}$ in these studies, may explain the different results compared to this study.

Although the use of biomaterials is essential for the increase of the repaired tissue volume within the bone defects, it has been demonstrated that the osteoconductive biomaterials occupy the space that would be filled by bone tissue, which is why the defects filled with biomaterials presented smaller amount of newly formed bone then the defects filled with coagulum. ${ }^{29}$ This finding was corroborated by the findings of the present study, in which the defects filled with DBB at 60 days in the CTR group and at both experimental periods in the CCP group, as well as defects filled with HA/TCP at 15 days in the CTR group, presented less bone compared to the defects that were not filled with biomaterials. The greatest impact of the impaired bone formation observed in the DBB subgroups may be associated with the reduced resorption rate of this biomaterial compared to the HA/TCP. ${ }^{27,28}$

The impairment of bone formation in defects not filled with biomaterials, or the delayed healing in grafts CSDs in the animals that have received cyclosporine, may be related to suppression of BMP2 protein and osteocalcin expression. These proteins have been related to osteoblastic differentiation and activity, ${ }^{30}$ and these proteins are also related to the maturation of the bone matrix. ${ }^{31}$ Regarding the suppression of the BMP2 caused by the cyclosporine administration, although it has been demonstrated that osteoblastic cells are not the only producers of this protein and that its absence does not blockage the process of bone regeneration, ${ }^{32}$ the presence of BMP2 has been shown to accelerate the bone healing process ${ }^{33}$ and this fact must have been especially important in this study because the bone formation in the experimental model used was probably guided by the periosteal cells that was previously related as drivers of the bone grafts healing. ${ }^{34}$ Furthermore, the results of this study was in accordance with studies that showed that the use of cyclosporin reduced the osteocalcin expression in post-extraction alveolar sockets in rats and this finding was associated with a delayed bone healing. ${ }^{35}$ Furthermore, the used of cyclosporine in patients submitted to renal transplantation was associated with the reduction of the bone mass and the decrease of the osteocalcin expression. ${ }^{36} \mathrm{In}$ addition, it was not observed in this study that the cyclosporine A administration altered the TGF $\beta 1$. Previous studies have shown an ambiguous effects of the cyclosporine A on TGF $\beta 1$ expression since it was showed that the cyclosporine A increased the TGFß1expression in inflamed gingiva, ${ }^{37}$ and reduced the TGFß1expression in human lung fibroblasts. ${ }^{38}$ This dual effect of the cyclosporine A observed in these different inflammatory conditions may be the reason of the absence of the interference of this drug on the TGF $\beta 1$ expression in the model used in this study. The action of cyclosporine reducing the volume of the mineralized tissues and the quality of the repaired bone tissue formed may mean that the waiting time for the implant installation after the bone grafting procedures with DBB and HA/TCP should be prolonged clinically in cyclosporine users compared with healthy individuals because the healing associated with the use of DBB and HA/ TCP may be slower in cyclosporine A users.

A methodological consideration of this study was the use of microcomputed tomography to analyze the volume of mineralized tissues. Although the volumetric measurement of the bone tissue has been reported as being of high accuracy, ${ }^{39}$ it was not possible to separate the bone tissue component from the biomaterials in this study. It is likely that the radiopacity of these biomaterials produces artifacts that hinder the correct identification of the bone and the biomaterial. ${ }^{40}$

The findings of this study should be interpreted with caution due to some limitations that prevent the extrapolation of these findings to daily clinical practice. The limited sample size prevented the use 
of parametric statistical tests and some evaluations that showed a trend of significant differences could have been detected if the sample size were larger. The cyclosporine A users have varied doses, according to the signs of rejection and the type of organ transplanted, ${ }^{4,5}$ therefore, the pre-clinical studies with controlled dosage provide only a clue as to what might occur in humans. Finally, transplanted patients are administered a range of medications and rarely use cyclosporine A as a monotherapy, and some of these drugs, such as glucocorticoids, have deleterious effect on mineral density ${ }^{41}$ and bone healing, ${ }^{42}$ which may potentiate the damage to bone repair in transplant patients using additional medications.

\section{Conclusion}

It can be concluded that the use of cyclosporine A impairs the bone formation in CSDs filled with coagulum and delays the healing of CSDs filled with DBB and HA/TCP, and this effect may be associated with reduced expression levels of the proteins related to bone turnover.

\section{Acknowledgements}

This study was financed by the Brazilian agencies FAPESP (Fundação de Amparo a pesquisa do Estado de São Paulo-2013/21559-6) and CAPES (Coordination for the Improvement of Higher Educated Personnel of Brazil-8540-12-8).

\section{References}

1. Vo AA, Lukovsky M, Toyoda M, Wang J, Reinsmoen NL, Lai CH, et al. Rituximab and intravenous immune globulin for desensitization during renal transplantation. N Engl J Med. 2008 Jul;359(3):242-51. https://doi.org/10.1056/NEJMoa0707894

2. Kraeuter M, Helmschrott M, Erbel C, Gleissner CA, Frankenstein L, Schmack B, et al. Conversion to generic cyclosporine A in stable chronic patients after heart transplantation. Drug Des Devel Ther. 2013 Nov;7:1421-6. https://doi.org/10.2147/DDDT.S54245

3. Duvoux C, Firpi R, Grazi GL, Levy G, Renner E, Villamil F. Recurrent hepatitis C virus infection post liver transplantation: impact of choice of calcineurin inhibitor. Transpl Int. 2013 Apr;26(4):358-72. https://doi.org/10.1111/tri.12065

4. Thierry A, Le Meur Y, Ecotière L, Abou-Ayache R, Etienne I, Laurent C, et al. Minimization of maintenance immunosuppressive therapy after renal transplantation comparing cyclosporine $\mathrm{A}$ /azathioprine or cyclosporine $\mathrm{A}$ /mycophenolate mofetil bitherapy to cyclosporine $\mathrm{A}$ monotherapy: a 10-year postrandomization follow-up study. Transpl Int. 2016 Jan;29(1):23-33. https://doi.org/10.1111/tri.12627

5. Söderlund C, Rådegran G. Immunosuppressive therapies after heart transplantation - the balance between under- and overimmunosuppression. Transplant Rev (Orlando). 2015 Jul;29(3):181-9. https://doi.org/10.1016/i.trre.2015.02.005

6. Yeo H, Beck LH, McDonald JM, Zayzafoon M. Cyclosporin A elicits dose-dependent biphasic effects on osteoblast differentiation and bone formation. Bone. 2007 Jun;40(6):1502-16. https://doi.org/10.1016/i.bone.2007.02.017

7. Lai CC, Chen WS, Chang DM, Tsao YP, Wu TH, Chou CT, et al. Increased serum fibroblast growth factor-23 and decreased bone turnover in patients with systemic lupus erythematosus under treatment with cyclosporine and steroid but not steroid only. Osteoporos Int. 2015 Feb;26(2):601-10. https://doi.org/10.1007/s00198-014-2910-3

8. Tsuruoka S, Kaneda T, Maeda A, loka T, Fujimura A. Dosing time-dependent variation of bone resorption by cyclosporin A in rats' femurs. Eur J Pharmacol. 2007 Jun;564(1-3):226-31. https://doi.org/10.1016/i.ejphar.2007.02.007

9. Moreira RO, Thiago LS, Oliveira FL, Balduino A, Borojevic R, Duarte ME, et al. Cyclosporine A, but not tacrolimus, is associated with impaired proliferation and differentiation of human osteoblast-like cells in vitro. Med Sci Monit. 2009 Mar;15(3):BR65-70.

10. Nassar CA, Nassar PO, Abi Rached RS, Holzhausen M, Marcantonio E Jr, Spolidorio LC. Effect of cyclosporin A on alveolar bone homeostasis in a rat periodontitis model. J Periodontal Res. 2004 Jun;39(3):143-8. https://doi.org/10.1111/j.1600-0765.2004.00739.x

11. Bozkaya G, Nart A, Uslu A, Onman T, Aykas A, Doğan M, et al. Impact of calcineurin inhibitors on bone metabolism in primary kidney transplant patients. Transplant Proc. 2008 Jan-Feb;40(1):151-5. https://doi.org/10.1016/i.transproceed.2007.11.040

12. Gurin L, Gohh R, Evangelista P. Pain syndrome with stress fractures in transplanted patients treated with calcineurin inhibitors. Clin Kidney J. 2012 Feb;5(1):13-6. https://doi.org/10.1093/ndtplus/sfr156

13. Montebugnoli L, Venturi M, Cervellati F, Servidio D, Vocale C, Pagan F, et al. Peri-implant response and microflora in organ transplant patients 1 year after prosthetic loading: a prospective controlled study. Clin Implant Dent Relat Res. 2015 Oct;17(5):972-82. https://doi.org/10.1111/cid.12207 
Gonçalves FC, Oliveira GJPL, Scardueli CR, Spin-Neto, R, Stavropoulos A, Marcantonio RAC

14. Duarte PM, Nogueira Filho GR, Sallum EA, Sallum AW, Nociti Júnior FH. Short-term immunosuppressive therapy does not affect the density of the pre-existing bone around titanium implants placed in rabbits. Pesqui Odontol Bras. 2003 Oct-Dec;17(4):362-6. https://doi.org/10.1590/S1517-74912003000400012

15. Sakakura CE, Marcantonio E Jr, Wenzel A, Scaf G. Influence of cyclosporin A on quality of bone around integrated dental implants: a radiographic study in rabbits. Clin Oral Implants Res. 2007 Feb;18(1):34-9. https://doi.org/10.1111/i.1600-0501.2006.01253.x

16. Sakakura CE, Margonar R, Sartori R, Morais JA, Marcantonio E Jr. The influence of cyclosporin a on mechanical retention of dental implants previously integrated to the bone: a study in rabbits. J Periodontol. 2006 Dec;77(12):2059-62. https://doi.org/10.1902/jop.2006.050290

17. Papageorgiou SN, Papageorgiou PN, Deschner J, Götz W. Comparative effectiveness of natural and synthetic bone grafts in oral and maxillofacial surgery prior to insertion of dental implants: systematic review and network meta-analysis of parallel and cluster randomized controlled trials. J Dent. 2016 May;48:1-8. https://doi.org/10.1016/i.jdent.2016.03.010

18. Vossen M, Edelstein J, Majzoub RK, Maldonado C, Perez-Abadia G, Voor MJ, et al. Bone quality and healing in a swine vascularized bone allotransplantation model using cyclosporine-based immunosuppression therapy. Plast Reconstr Surg. 2005 Feb;115(2):529-38. https://doi.org/10.1097/01.PRS.0000148373.86487.04

19. Espitalier F, Durand N, Rémy S, Corre P, Sourice S, Pilet P, et al. Development of a cyclosporin-A-induced immune tolerant rat model to test marrow allograft cell type effects on bone repair. Calcif Tissue Int. 2015 May;96(5):430-7. https://doi.org/10.1007/s00223-015-9970-z

20. Ekelund A, Aspenberg P, Nilsson O. No effect of immunosuppression with cyclosporin A detected on bone ingrowth into cancellous allo- and xenografts in the rat. Acta Orthop Scand. 1999 Oct;70(5):491-6. https://doi.org/10.3109/17453679909000987

21. Queiroz TP, Souza FA, Okamoto R, Margonar R, Pereira-Filho VA, Garcia Júnior IR, et al. Evaluation of immediate bone-cell viability and of drill wear after implant osteotomies: immunohistochemistry and scanning electron microscopy analysis. J Oral Maxillofac Surg. 2008 Jun;66(6):1233-40. https://doi.org/10.1016/i.joms.2007.12.037

22. Fornoni A, Cornacchia F, Howard GA, Roos BA, Striker GE, Striker LJ. Cyclosporin A affects extracellular matrix synthesis and degradation by mouse MC3T3-E1 osteoblasts in vitro. Nephrol Dial Transplant. 2001 Mar;16(3):500-5. https://doi.org/10.1093/ndt/16.3.500

23. Sakakura CE, Margonar R, Holzhausen M, Nociti FH Jr, Alba RC Jr, Marcantonio E Jr. Influence of cyclosporin A therapy on bone healing around titanium implants: a histometric and biomechanic study in rabbits. J Periodontol. 2003 Jul;74(7):976-81. https://doi.org/10.1902/jop.2003.74.7.976

24. Sun L, Blair HC, Peng Y, Zaidi N, Adebanjo OA, Wu XB, et al. Calcineurin regulates bone formation by the osteoblast. Proc Natl Acad Sci USA. 2005 Nov;102(47):17130-5. https://doi.org/10.1073/pnas.0508480102

25. Sanz-Sánchez I, Ortiz-Vigón A, Sanz-Martín I, Figuero E, Sanz M. Effectiveness of lateral bone augmentation on the alveolar crest dimension: a systematic review and meta-analysis. J Dent Res. 2015 Sep;94(9 Suppl):128S-42S. https://doi.org/10.1177/0022034515594780

26. Wang RE, Lang NP. Ridge preservation after tooth extraction. Clin Oral Implants Res. 2012 Oct;23 Suppl 6:147-56. https://doi.org/10.1111/j.1600-0501.2012.02560.x

27. Cordaro L, Bosshardt DD, Palattella P, Rao W, Serino G, Chiapasco M. Maxillary sinus grafting with bio-oss or straumann bone ceramic: histomorphometric results from a randomized controlled multicenter clinical trial. Clin Oral Implants Res. 2008 Aug;19(8):796-803. https://doi.org/10.1111/j.1600-0501.2008.01565.x

28. Martinez A, Balboa O, Gasamans I, Otero-Cepeda XL, Guitian F. Deproteinated bovine bone vs. beta-tricalcium phosphate as bone graft substitutes: histomorphometric longitudinal study in the rabbit cranial vault. Clin Oral Implants Res. 2015 Jun;26(6):623-32. https://doi.org/10.1111/clr.12349

29. Carmagnola D, Adriaens P, Berglundh T. Healing of human extraction sockets filled with Bio-Oss. Clin Oral Implants Res. 2003 Apr;14(2):137-43. https://doi.org/10.1034/j.1600-0501.2003.140201.x

30. Ryoo HM, Lee MH, Kim YJ. Critical molecular switches involved in BMP-2-induced osteogenic differentiation of mesenchymal cells. Gene. 2006 Jan;366(1):51-7. https://doi.org/10.1016/i.gene.2005.10.011

31. Zoch ML, Clemens TL, Riddle RC. New insights into the biology of osteocalcin. Bone. 2016 Jan;82:42-9. https://doi.org/10.1016/i.bone.2015.05.046

32. McBride-Gagyi SH, McKenzie JA, Buettmann EG, Gardner MJ, Silva MJ. Bmp2 conditional knockout in osteoblasts and endothelial cells does not impair bone formation after injury or mechanical loading in adult mice. Bone. 2015 Dec;81:533-43. https://doi.org/10.1016/i.bone.2015.09.003

33. Zeng JH, Qiu P, Xiong L, Liu SW, Ding LH, Xiong SL, et al. Bone repair scaffold coated with bone morphogenetic protein-2 for bone regeneration in murine calvarial defect model: systematic review and quality evaluation. Int J Artif Organs. 2019 Jul;42(7):325-37. https://doi.org/10.1177/0391398819834944 
- Cyclosporine A impairs bone repair in critical defects filled with different osteoconductive bone substitutes

34. Chappuis V, Gamer L, Cox K, Lowery JW, Bosshardt DD, Rosen V. Periosteal BMP2 activity drives bone graft healing. Bone. 2012 Oct;51(4):800-9. https://doi.org/10.1016/i.bone.2012.07.017

35. Ozcan-Kucuk A, Alan H, Gul M, Yolcu U. Evaluating the effect of resveratrol on the healing of extraction sockets in cyclosporine a-treated rats. J Oral Maxillofac Surg. 2018 Jul;76(7):1404-13. https://doi.org/10.1016/i.joms.2018.02.030

36. Heaf J, Tvedegaard E, Kanstrup IL, Fogh-Andersen N. Bone loss after renal transplantation: role of hyperparathyroidism, acidosis, cyclosporine and systemic disease. Clin Transplant. 2000 Oct;14(5):457-63. https://doi.org/10.1034/j.1399-0012.2000.140503.x

37. Ma S, Liu W, Liu P, Liu J, Chen L, Qin C. Tanshinone IIA treatment alleviated the rat gingival connective tissue overgrowth induced by cyclosporine A. J Periodontal Res. 2016 Oct;51(5):567-76. https://doi.org/10.1111/ire.12335

38. Yamazaki R, Kasuya Y, Fujita T, Umezawa H, Yanagihara M, Nakamura H, et al. Antifibrotic effects of cyclosporine A on TGF- $\beta 1$-treated lung fibroblasts and lungs from bleomycin-treated mice: role of hypoxia-inducible factor-1 $\alpha$. FASEB J.

2017 Aug;31(8):3359-71. https://doi.org/10.1096/fj.201601357R

39. Abbassy MA, Watari I, Soma K. The effect of diabetes mellitus on rat mandibular bone formation and microarchitecture. Eur J Oral Sci. 2010 Aug;118(4):364-9. https://doi.org/10.1111/j.1600-0722.2010.00739.x

40. Trisi P, Rebaudi A, Calvari F, Lazzara RJ. Sinus graft with biogran, autogenous bone, and PRP: a report of three cases with histology and micro-CT. Int J Periodontics Restorative Dent. 2006 Apr;26(2):113-25.

41. Lippuner K, Casez JP, Horber FF, Jaeger P. Effects of deflazacort versus prednisone on bone mass, body composition, and lipid profile: a randomized, double blind study in kidney transplant patients. J Clin Endocrinol Metab. 1998 Nov;83(11):3795-802. https://doi.org/10.1210/jc.83.11.3795

42. Li J, Wang X, Zhou C, Liu L, Wu Y, Wang D, et al. Perioperative glucocorticosteroid treatment delays early healing of a mandible wound by inhibiting osteogenic differentiation. Injury. 2012 Aug;43(8):1284-9. https://doi.org/10.1016/i.injury.2012.04.014 